\title{
Promotion Determinants in Corporate Hierarchies: An Examination of Fast Tracks and Functional Area*
}

\author{
Christian Belzil ${ }^{\dagger}$ \\ CREST, CNRS, Ecole Polytechnique, Universite de Paris-Saclay and IZA \\ Michael Bognanno $\ddagger$ \\ Temple University and IZA \\ François Poinas ${ }^{\S}$ \\ Toulouse School of Economics, University of Toulouse Capitole
}

January 30, 2018

\begin{abstract}
This article estimates a dynamic reduced-form model of intra-firm promotions using an employer-employee panel of over 300 of the largest corporations in the U.S. in the period from 1981 to 1988. The estimation conditions on unobserved individual heterogeneity and allows for both an endogenous initial condition and sample attrition linked to individual heterogeneity in demonstrating the relative importance

*We are grateful to an anonymous referee and seminar participants at the 2010 ASFE annual congress in Paris, the 2012 EEA annual conference in Málaga and the 2015 Conference on Tournaments and Promotions at Hitotsubashi University for useful comments.

$\dagger$ Ecole Polytechnique, Economics Department, Palaiseau F-91128 cedex, France. Email: christian.belzil@polytechnique.edu

†Temple University, Department of Economics, Philadelphia, PA 19122. Email: bog-

$\S$ Toulouse School of Economics, University of Toulouse Capitole, Toulouse F-31015 cedex, France. Email: francois.poinas@tse-fr.eu
\end{abstract} nanno@temple.edu 
of variables that influence promotion. The role of the executive's functional area in promotion is considered along with the existence and source of promotion fast tracks. We find that while the principal determinant of promotions is unobserved individual heterogeneity, functional area has a high explanatory power, resulting in promotion probabilities that differ by functional area for executives at the same reporting level and firm. No evidence is found that an executive's recent speed of advancement in pay grade has a positive causal impact on in-sample promotions after conditioning on the executive's career speed of advancement, except for the lowest level executives the data. Fast tracks appear to largely result from heterogeneity in persistent individual characteristics, not from an inherent benefit in recent advancement itself. 
JEL classification: C33, M5, M51

Keywords: Promotion, Fast Track, Functional Area, Dynamic Discrete Choice 


\section{Introduction}

This paper considers the promotion of high-level American executives. A dynamic reduced-form model of promotion outcomes is estimated using an employer-employee panel of over 300 of the largest corporations in the U.S. in the period from 1981 to 1988. The model demonstrates the relative importance of variables that influence promotion, examines the existence and source of fast tracks in promotion while conditioning on unobserved individual heterogeneity in promotion and allowing for both an endogenous initial condition and sample attrition linked to individual heterogeneity. We also consider the role of the executive's functional area (accounting, marketing, etc.) in promotion.

This paper contributes to earlier investigations of promotion in the personnel economics literature and in the management literature. We corroborate findings on promotion regarding the effect of hierarchical level and the importance of unobserved heterogeneity in the personnel economics literature (Baker, Gibbs and Holmstrom, 1994a, 1994b, Lazear, 1992). Firm studies in both literatures find evidence of promotion fast tracks but do not empirically determine the source of fast tracks. By analyzing the role played by the speed of past advancement on promotion outcomes, we are able to evaluate implications from models of job assignment that regard whether the source of promotion fast tracks is simply superior worker ability (persistent unobserved individual heterogeneity to the researcher) or whether rapid promotion has its own positive causal impact on worker promotability due to the potential signal it reveals to the labor market of high worker ability. Findings supportive of the signaling role of promotions are appearing in the personnel economics literature (DeVaro and Waldman 2012, Bognanno and Melero 2012, Okamura 2011, Cassidy, DeVaro, and Kauhanen 2012). At the same time, investigating the impact that functional area may have on promotion outcomes contributes to the management science literature on this question (Vroom and MacCrimmon 1968, Forbes and Piercy 1991) and is of general interest.

This paper is related to a previous work (Belzil and Bognanno, 2010) that also estimated a dynamic model of promotion in order to identify promotion determinants and the source of fast tracks. However, there are four central improvements of this paper over the previous work of Belzil and Bognanno.

First, the prior paper employed advancement in reporting level towards the CEO position as the measure of promotion. In this paper, we use changes 
in job titles coupled with nominal pay grade midpoint increases to define promotion. We show that this new definition of promotion exhibits more power in explaining wages than the previous promotion measure. Linking promotion to changes in job title is also more standard in the literature and gives the results greater comparability. One difference between these alternative definitions is that the incidence of demotions is much lower with the job title/pay grade change definition. Consistent with the findings for the firm studied in BGH, demotions appear rare in U.S. corporate data.

Second, the prior paper measured past speed of advancement in reporting level (employing the executive's reporting level, age and years of education to construct speed) to capture the speed of past promotion. Because advancement in level can vary in significance both within and across firms, the speed measure employed was not perfectly comparable across executives. This paper measures advancement speed as the speed of pay grade attainment (defined as the real pay grade midpoint divided by the worker's age) instead, a unit of measurement based on time and money that is universal across firms and workers.

Third, there is significant attrition from the sample and to allow for the possibility that individual sample attrition is correlated with promotion probabilities, this paper models the response probability as a function of observed and unobserved individual heterogeneity. While our model does not allow for a causal effect of promotion expectations on the occurrence of non-response, it nevertheless captures the spurious correlation that may exist between firm reporting decisions and executive unobserved ability. Last, this paper includes an analysis of the role of functional area on promotion that was not examined previously and has received scant attention in the economics literature.

The central findings of Belzil and Bognanno and this paper complement each other. The prior paper found that after conditioning on unobservable heterogeneity, the speed of past advancement in level negatively influenced subsequent advancement for most executives in the sample population. Furthermore, the overall influence across all executives in the sample of the speed of past promotion on subsequent promotion was negligible. The fast tracks documented in the literature and apparent in examining the raw data appeared to arise largely from unobserved individual heterogeneity (for instance, some workers being of greater ability) and not from rapid past promotions providing an inherent advantage in regards to subsequent promotions.

Interestingly, for a minority of executives, past speed of advancement 
aided promotion and a casual fast track was found. These executives tended to be at lower levels with less education and tenure. This is noteworthy because promotion signals would intuitively be expected to be the strongest for those promoted with the least education and needing the least time to gain the necessary experience. In fact, DeVaro and Waldman (2012) derive the theoretical implication that, for less educated workers, both the performance level required for promotion and the wage change upon promotion are higher. They also state that these implications hold more strongly for initial promotions than for subsequent promotions. This suggests that the strongest signals to the outside labor market should come from the promotion of inexperienced, less educated, lower level executives without a history of prior promotions.

This paper finds a weakly negative marginal effect of the recent speed of promotion (from in-sample promotions) on the probability of promotion after conditioning on the executive's career speed of advancement measured when they first appear in the sample. Since fast tracks are apparent in the raw data and disappear in econometric work after controlling for unobservable individual heterogeneity, fast tracks appear to result from the persistent benefit of being more able. This result is consistent with the prior paper.

In another result that is consistent in flavor with the prior paper, insample promotions do have a positive effect on the promotion probability of some executives. This paper finds that in-sample promotions have a positive effect on promotion probabilities for executives at least five reporting levels beneath the CEO, no significant effect on the promotion probabilities of executives two to four levels beneath the CEO and a negative effect on the promotion probabilities of executives reporting to the CEO. This is intriguing because it suggests that there is a role for promotion signaling generating a fast track for the workers lower in the hierarchy, even though for executives taken on the whole, to the extent fast tracks are evident, they appear to result simply from more able executives achieving promotion more quickly on a persistent basis.

Regarding the determinants of promotion, when promotion is defined as a change in job title resulting in a higher pay grade, the most influential determinant of promotion by far is unobserved individual heterogeneity. Determinants of less importance are functional area, career advancement speed (measured as the executive's inflation adjusted pay grade midpoint divided by the executive's age as of the executive's first appearance in the sample), human capital (age and education), firm variables (profits, sales and size), 
tenure and newcomer status at the firm and reporting level in the firm. Rates of promotion diminish with advancement in level and age. Career advancement speed, on which unobserved individual heterogeneity is conditioned, has a positive effect on promotion probabilities but the recent speed of advancement has no significant effect. Promotion probabilities are negatively correlated with sample attrition. Overall, the promotion process can be characterized as a static discrete outcome model in which all serial correlation can be accounted for by persistent individual unobserved factors.

The next section of the paper discusses the economics literature on promotions. Section 3 contains a discussion of the data. Section 4 contains the empirical model and results are discussed in Section 5. Concluding remarks are found in section 6 .

\section{Promotions in the Economics Literature}

Much of the influential work on firm hierarchies comes from single firm studies of personnel records that allow for a comprehensive examination of the internal workings of the firm. Key early papers include Baker, Gibbs and Holmstrom (here after BGH, 1994a, 1994b) and Lazear (1992). BGH examined twenty years of personnel data for all management employees of a single, medium-sized U.S. firm in a service industry. They relied on observed job transitions in the data to define levels within the firm. Since there were many lengthy careers with movement through numerous job titles, they were able to precisely identify the firm's hierarchical levels. Eight levels and seventeen primary job titles covered over $99 \%$ of management level employment. Underscoring the gains to promotion, BGH (1994b) found that levels alone explained about $70 \%$ of the variance in pay across employees in a given year. Their results regarding promotion included: evidence of fast tracks; ${ }^{1}$ workers promoted quickly from low levels were promoted subsequently more quickly;

\footnotetext{
${ }^{1}$ Evidence for the existence of promotion fast tracks was found also in Rosenbaum's (1979) study of a large corporation, in Chiappori, Salanie and Valentin's (1999) study of a French state-owned firm, in the Seltzer and Merrett's (2000) study of the Union Bank of Australia, in Treble, van Gameren, Bridges and Barmby's (2001) study of a large British financial sector firm, in Dohmen, Kriechel and Pfann's (2004) study of a Dutch aircraft manufacturer, in Gibbs and Hendriks's (2004) study of a large US corporation and in Kauhanen and Napari's (2012) study of 5,000 firms in the Finnish manufacturing sector. Howard and Bray (1988) found that Bell System managers with more significant job challenges in their initial years of employment had greater advancement at year twenty.
} 
the rate of promotion was higher at low levels in hierarchy; ${ }^{2}$ promotion rates that fell with firm tenure; a positive correlation between rapid promotion and firm exit. BGH (1994b) found evidence of serial correlation in real wage growth for managers that persisted after accounting for observable differences between individuals. Observable characteristics explained only part of heterogeneity across managers. As greater wage growth was associated with a greater speed of promotion, BGH suggest that the presence of an unobserved variable, such as ability, drives both promotions and wage growth.

Clemens (2012) used the BGH data in finding that some positions have higher rates of promotions than others at the same level in the firm hierarchy even after controlling for observable worker characteristics. However, he did not find clear evidence of a persistent effect on promotion of advancement from a position characterized by a high rate of promotion. He suggests that fast tracks may be indicative of some jobs providing faster human capital acquisition and consequently more rapid promotion, as well as of some individuals having higher innate ability.

A similar suggestion was made by Ariga, Ohkusa and Brunello (1999). They found in their study of a Japanese firm that serial correlation in promotion (fast tracks) was evident even with the inclusion of employee fixed effects. They suggest that differences in individual promotion outcomes may result from more than just individual differences in time invariant innate ability and point to a role for job heterogeneity. The form of job heterogeneity put forth is one in which some low level jobs feature high intensity training and fast learning workers, training that serves these workers well in the current job and in more senior ones.

Lazear (1992) analyzed thirteen years of personnel records from a large manufacturing firm. Lazear's findings included that those who changed jobs tended to have higher starting pay upon hire and this also increased the likelihood of higher relative career pay. Hence, differences in starting pay well explained differences in career earnings between workers and made starting pay and the first job important. This account of promotions being persistently influenced by factors at the time of hire is suggestive of fast-tracks. Lazear states that workers may be sorted into their initial job assignment on the basis of real differences between them (unobserved individual heterogeneity to the researcher) or on the basis of a first impression that nevertheless

\footnotetext{
${ }^{2}$ Evidence of higher rates of promotion in lower hierarchical levels was also noted in Treble, van Gameren, Bridges and Barmby (2001).
} 
carries a career-long effect. This unanswered question regarding the source of career-long advantages enjoyed by some workers relates to explanations of promotion fast tracks in job assignment models under alternative assumptions and is considered in this paper. Promotion fast tracks can result from both differences between workers in innate ability and from the advantage gained through early initial promotion. ${ }^{3}$

The job assignment model provides a theoretical basis for the existence of fast tracks. We describe two models that both derive promotion fast tracks, Gibbons and Waldman (1999) in the case of job assignment with full information and Bernhardt (1995) in the case of asymmetric learning. Both models consider a firm with three exogenously determined jobs that allow for two promotions, which is the minimum number necessary for a discussion of fast tracks. Identical competitive firms, with labor as the only input, assign workers to exogenously determined jobs. Output in each job is the sum of two components, one a constant term that varies by job but is independent of the worker and one that depends on the effective ability of the worker. Effective ability is a function of the innate ability of each worker and the worker's accumulated labor market experience. Promotions occur when a worker's output is greater in a higher level job than in the current job. The parameters determining output in the three job levels are set so as to differentially value effective ability such that workers, as they gain experience, progress through the jobs sequentially. Because workers differ in innate ability, they grow in effective ability with labor market experience at different rates and therefore the time necessary to achieve promotion varies. Fast tracks result because workers with rapid initial promotions also have more rapid subsequent promotions. This source fast tracks is simply due to more able workers achieving both promotions more rapidly. The speed of initial promotion does not have a causal effect on the speed of the subsequent promotion. The relative pace of both promotions is driven by differences in worker ability. This is the only source of fast tracks when the employer and the outside labor market are fully informed.

In job assignment models in which the current employer is fully informed and outside firms learn worker ability through the signal provided by observing the workers current and previous job assignments, past promotions also

\footnotetext{
${ }^{3}$ We draw these implications from two classes of models: the case of full information (e.g., Gibbons and Waldman, 1999) and the case of asymmetric learning (e.g., Waldman, 1984, and Bernhardt, 1995).
} 
have an inherent effect on promotion outcomes after conditioning on worker ability. Higher wages must be paid to workers whose promotions signal high ability to outside firms. Since workers who have been rapidly promoted in the past have already been signaled to be of high ability, their subsequent promotion is less costly and, hence, speedy past promotions will have a positive causal effect on the probability of subsequent promotion. This implies that serial persistence in individual promotion histories may simultaneously result from both persistent unobserved heterogeneity and state dependence explained by past promotion outcomes. Stated differently, fast tracks may arise both because of differences in ability and because of the advantage given to fast climbers.

When fast tracks arise out of differences in ability, we call this a spurious fast track because rapid initial promotion provides no inherent advantage in subsequent promotion. The latter reason gives rise to what we call a causal fast track, promotions that come more quickly because of the speed of past promotions. Our empirical method will distinguish between these two potential sources of fast-tracks. Evidence of casual fast tracks supports the notion of promotion signaling in the job assignment models with asymmetric information.

Aside from a consideration of fast-tracks, we examine the effect on promotion of current labor market conditions, labor market conditions present at the time of hire and the executive's functional area. Kwon, Milgrom and Hwang (2010) examined the long-term effects on worker promotion and wages of the employment rate present at the time of entry into the labor market using Swedish employer-employee matched data and data from a single US firm. They found worker cohorts that entered the labor market during strong business cycle conditions achieved higher ranks and more rapid promotion. The effect on promotions of business cycle conditions at the time of labor market entry resulted in persistent cohort effects. Beaudry and DiNardo (1991) used data from the Current Population Survey and the Panel Study of Income Dynamics to examine the link between current wages and the history of labor market conditions experienced by workers to determine whether the results are better explained by a spot market model or an implicit contract model. They find support for an implicit contract model with costless mobility. In this model, wage are set at the beginning of the contract but must be increased if labor market conditions improve to prevent workers from leaving for better offers. In this case, the lowest unemployment rate during the employment term will be negatively correlated with the current 
wage rate. They found controlling for the lowest unemployment rate during the employment term caused the contemporaneous unemployment rate to be insignificant.

The potential role of functional area on promotion has received little empirical or theoretical attention in the economics literature. However, this topic has appeared in the management literature. Vroom and MacCrimmon (1968) found that promotion opportunities varied with functional area and were better in finance and marketing. Forbes and Piercy (1991) found that the functional area backgrounds of CEOs varied by industry and, with regards to the eventual CEOs, the time to reach various top positions in the organization varied by functional area. At the outset, it should be clear that our objective is not to treat functional area as an endogenous choice variable. We treat functional area as an element of the initial endogenous condition. Our analysis is based on two possible interpretations. First, if firms assign individuals to functional areas based on skills and factors that are correlated with factors explaining promotability, we may expect the initial functional area to account for a non-trivial share of persistent unobserved heterogeneity. A second possibility, more in line with functional area having a causal effect, is that individuals move across different possible functional areas during their careers, targeting those areas that are known to provide better promotion opportunities. Better promotion opportunities could exist in functional areas that provide experience that is more useful in upper management positions or that feature a lesser span of control, reducing the number of executives competing for promotions. If so, the promotion process should display serial correlation, even after conditioning on unobserved heterogeneity. Although we cannot distinguish between these two hypotheses, both of them imply that after some elapsed career duration, the prevailing functional area of a given executive is likely to exhibit some correlation with subsequent promotion outcomes.

\section{Data}

The proprietary panel data set used in this study provides information on over 30,000 executives working at over 300 of the largest firms in the United States during the period from 1981 to 1988. It was assembled by a major compensation consulting firm based on annual surveys completed by a hu- 
man resource professional at the respondent company on both the company and individual executives. Respondent companies paid to participate in the survey, for which they received a report on the competitiveness of their pay levels relative to the pay levels of executives at comparable firms.

The respondent company decided the number of executives to include each year and whether to participate annually or on a less frequent basis. The guidelines provided to firms suggested that they provide data on a representative sample of at least 75 executives in a variety of job families, managerial levels and organizational units. When a job title was shared by many executives and firms did not wish to report on each, they were asked to report on several representative cases. Respondent companies submitting data on more than 120 executives in a given year were subject to an additional fee. The mean number of executives reported on annually per firm was roughly 80.

The database reveals information on individual, job and firm characteristics, including: age, years of education, functional area, job title, firm tenure, base pay, bonus pay, reporting level, industry, firm profits, sales, and employment. Gender is not available in these data. The consulting firm took measures to ensure that the information for each individual and company was valid and complete. All survey data were run through a series of error checking programs and subsequently staff reviewed for follow up with the respondent company when inconsistencies were noted. The information submitted on firm characteristics was accompanied by the respondent company's most recent annual report and proxy statement to ensure the consistency of the financial data.

A unique identifier assigned to each individual allows them to be tracked over time in their given firm. However, the movement of an individual between firms cannot be tracked as they would be assigned a new identifier in the subsequent company. An individual's disappearance from these data does not necessarily indicate an exit from the firm or a transition within the firm, as the respondent company elects which jobs to include each year.

Promotion is conventionally defined to be a worker's movement to a superior position or rank in the firm. While this paper and our prior paper differ in their definition of promotion, both papers employ a definition of promotion that is consistent with the conventional definition since this paper considers a change in job title resulting in a higher pay grade (superior position) and the prior paper defines promotion as an improvement in reporting level (rank). However, there is evidence to suggest that workers define promotion more 
broadly than the conventional definition.

Pergamit and Veum (1999) find that requiring a job change in defining promotion causes a severe underestimation of what workers deem a promotion using the 1990 National Longitudinal Survey of Youth. The survey asked workers to report if they were promoted and to select the type of change that took place among eight choices. The individual workers surveyed defined promotion broadly with most self-reported promotions not involving changes in job duties. Workers continuing to perform basically the same job duties and those in the same positon but having a position upgrade accounted for $57 \%$ of workers reporting a promotion. Despite not involving a change in job duties, these promotions were associated with wage growth. Promotions entailing moving to a different job within the firm were found by Pergamit and Veum to occur in minority of self-reported promotions. Workers taking a higher level job in a different section, taking a newly created position with more responsibilities, moving into their supervisor's job or receiving a promotion after a re-organization accounted for just 38\% of those reporting a promotion. It is worth noting that for $11 \%$ of those reporting promotions, a wage increase was not noted. Perhaps because most self-reported positions did not involve a change of job, only $33 \%$ of those promoted reported that other people were considered for the promotion.

In considering how promotion should be defined generally, there are at least three considerations. First, the definition of promotion will factor into the level of heterogeneity in promotion. At the broadest level, any improvement in the conditions of employment might be considered a promotion by workers. Using a broad definition, a greater level of heterogeneity in the promotions recorded will result because some promotions will entail rising in rank or moving to a superior job while others will simply reflect an upgrade to the current position or some other improvement in employment. Second, the promotion definition adopted empirically should be consistent with theoretical model being considered. For instance, tournament theory is premised on the notion of competitively determined worker advancement in a hierarchy. Success in a tournament should be manifested though an improvement in rank. Tournament theory is silent on the phenomena of upgrades to a worker's current position. Hence, including upgrades to the same position in the definition of promotion is not appropriate. Similarly, the job assignment model assumes that workers progress through jobs that differ in how they translate employee ability into output. It is also silent on the phenomena of upgrades to a worker's current position. In evaluating the predictions of the 
job assignment model, a consistent definition of promotion entails movement to a superior job title. Last, a definition that requires movement to a superior job title is more standard in the literature and will facilitate comparisons to the literature.

In these firm-reported data, worker self-assessed promotions are not available. The basic decision in defining promotion is whether the basis for promotion should be changes in the reporting level, pay grade or job title. Firms have more job titles than pay grades and more pay grades than reporting levels and any of these metrics can change without necessarily causing a corresponding change in the others. As well, not everyone in a particular class (reporting level, pay grade or job title) will necessarily share the two alternative hierarchy measures with others in their firm and class.

Using the reporting level as a measure of promotion is easy since it is already ordered. In previous papers, we used changes in reporting level to define promotion. The disadvantage of reporting level is that it might change for those below the CEO if, for instance, the firm creates a new level in the reporting hierarchy by filling a new top level position. This does not constitute a demotion in the sense of falling to a lesser position for those below the new level, though adding a rung between an executive and the CEO may make the climb to the top longer. Another disadvantage is that level changes in the data appear to be a somewhat noisy measure and likely overstate the extent of demotions.

Using pay grade advancement to define promotion requires distinguishing the promotion-induced advance in an executive's pay grade midpoint from the normal annual advance in pay grade midpoints. Programming this distinction would be difficult. Simply coding as promotions cases in which an executive's pay grade midpoint advanced more than the firm mean pay grade advancement is not sufficient because pay grade midpoints do not always advance uniformly, sometimes the pay grades of higher level executives advance more in percentage terms than the lower pay grades.

In this paper, we use job title changes to define promotion. This measure has been widely used by others studying personnel data and enhances the comparability of our results. It is also consistent with the notion of promotion in the job assignment model. The drawback is that we assume that a person's status in an organization cannot change as long as the job title remains the same. Anecdotal evidence suggests that an executive's place in the pecking order and responsibilities in a firm may change even though the executive continues in the same job title. Overlooking this issue, job title changes must 
still be ordered on some basis to determine if they are promotions, lateral moves or demotions.

We define promotions as changes in job title that result in the executive being assigned a higher nominal pay grade midpoint. Lateral moves are defined as job title changes that result in the executive being assigned the same nominal pay grade midpoint. Demotions are defined as job title changes that result in the executive being assigned to a lower nominal pay grade midpoint. Non-movers have no change in their job title. Classifying transitions into these four types shows demotions to be rare, consistent with BGH. It is important to note that we are not defining promotions based on a job title change and an increase in the executive's actual base pay but rather an increase in the pay grade. A pay grade is the specified range in which a position's base salary may vary and is a typical aspect of corporate salary structures.

Table 1 provides basic summary statistics for the variables used in the likelihood estimations that are the next step in this paper. This table limits the sample to only executives who appear in the first and second years of the data (1981 and 1982). This accounts for sample size differences with other tables that do not impose this restriction. The intent of this is to show the extent of sample attrition and the progress in earnings for executives remaining in the data over the sample period. Means and standard deviations by year are provided for compensation, promotion rates and some firm variables. Means and standard deviations for executive characteristics in 1981 are also reported.

Table 2 considers the importance of reporting level and job title promotions in pay determination. Reporting level is measured as the number of reporting levels an executive is from the $\mathrm{CEO}(\mathrm{CEO}=$ reporting level 1$)$. The job title promotion index for purposes of this table is set to 0 in the first year an executive appears in the data and is updated by +1 for subsequent promotions and -1 for demotions. This gives it a structure similar to reporting level. Of course, reporting level identifies a layer in the hierarchy of the firm while the job title promotion index only indicates the movements up and down in job title without specifying the executive's position in the hierarchy. This is evident in the top panel of Table 2 that shows the reporting level to be more influential in pay determination. It should be noted that larger values for reporting level indicate being further from the top of the company. Hence, the coefficient on reporting level has a negative value. Executives one level closer to the CEO earn $23 \%$ more in total compensation (the sum of 
base and bonus pay). A one-unit rise in the promotion index increases pay by $13 \%$.

The bottom panel of Table 2 includes individual fixed effects. The estimation of the coefficient on reporting level is now based on executive's changing reporting levels in the data since the executive's mean pay over the sample is picked up in the individual intercept term. In this estimation, job title changes have a much larger impact on earnings than changes in reporting level. Job title changes are a better indicator of pay changes than changes in reporting level after accounting for worker fixed effects. This argues in favor considering job titles in defining promotion.

Table 3 provides pay changes and transitions between an executive's first and second years in the data, between the second and third years and between the third and fourth years with the changes grouped by the executive's initial transition between the first and second years. Between each executive's first two years in the data, $90 \%$ are non-movers, $8 \%$ are promoted, $1.2 \%$ are lateral movers and $0.7 \%$ are demoted. As might be expected, the percentage changes in the total compensation, base pay and bonus pay are largest for the promoted and smallest for the demoted (total compensation is merely the sum of the base pay and annual bonus and does not include other forms of compensation that might increase upon promotion).

Changes taking place in pay between an executive's second and third years and third and fourth years show that the beneficial effect of promotion over non-movement persists but is less evident in later years. Lateral movers, with higher rates of subsequent promotion, have the highest pay increases in years subsequent to the initial move. The lesser pay growth for the demoted persists but lessens in later years.

Changes taking place between an executive's second and third years in regards to transitions show that those who moved previously are more likely to have subsequent moves. Non-movers initially have about a $90 \%$ chance of remaining non-movers. Those with an initial change in job title combined with any type of movement in pay grade are substantially more likely to be promoted subsequently. The demoted are much more likely to be demoted again. Even in the year just following a promotion, the promoted executives have promotion probabilities about $75 \%$ greater than non-movers $(13.8 \%$ versus $7.9 \%$ ). This differential persists two years after promotion, initially promoted executives are $70 \%$ more likely than non-movers to be promoted between years three and four (15.1\% versus $8.9 \%)$. The higher subsequent rate of promotion for those promoted between their first two years in the raw 
data is in accord with the notion of fast tracks, higher rates of subsequent promotion for those promoted previously. It's surprising that fast tracks appear evident even in regards to the in sample promotions in the very next year for experienced executives occupying jobs at top reporting levels in the firm where longer tenure in position might be expected before another promotion.

Table 4 considers variables that might serve as leading indicators of promotion. Executives are grouped according to the transition they experience between their second and third year in the data. Transitions between the second and third years are used to allow pay changes to be constructed based on prior data (years one and two). The sample is restricted to executives present for at least three consecutive years. It is evident from the table that promoted executives received larger pay increases prior to promotion, followed by lateral movers and non-movers. The demoted between years two and three also received the smallest pay increases between years one and two. The result that wage increases predict subsequent promotions was also noted in BGH and a theoretical model with an explanation for this result is found in Gibbons and Waldman (1999).

Table 4 also shows that promoted executives tend to be younger and have less firm tenure prior to promotion. The promoted are followed in youth and inexperience by lateral movers and non-movers. These findings alone would say little about fast tracks since promotions are more frequent at the lower levels in the firm occupied by younger workers. However, promoted executives also tend to be younger than average among workers in their same job and firm prior to promotion. While the differences in age minus the firm/job mean age are small, less than a full year, this is consistent with the operation of fast tracks. Also consistent with fast tracks, the promoted spent the least time in their positions prior to promotion while the non-movers spent the most time. Differences between the groups in education are slight but orderly. The promoted are the most educated and the demoted are the least educated. All three classes of job title changers were likely to have had a prior job title change, particularly a previous promotion. Age, education, tenure and level are included in the formal empirical models of promotion to follow. 


\section{Econometric Model}

We build a dynamic model of promotion in which the probability of promotion at a point in time is a function of individual and firm characteristics and the executive's career advancement speed. We model individual unobserved heterogeneity in a flexible way to account for persistent characteristics unobserved by the econometrician that affect promotions (like innate ability or motivation). ${ }^{4}$

Our model addresses two important issues. The first one is the so called initial condition problem. The initial level at which the worker is observed in a firm is likely to be influenced by permanent unobserved factors that also affect the subsequent movement of the worker in the firm. We address this issue using Wooldridge's (2005) method by conditioning on the distribution of unobserved heterogeneity on the initial level. The second issue concerns endogenous attrition. As shown in Table 1, a significant number of executives leave the sample each year. Dropping out of the sample at a point in time is caused either by the firm not participating in the survey at all or not reporting on an executive still with the firm or no longer with the firm. As mentioned in the data section, firms were asked to report on a representative sample of jobs, levels and units. In the case of job titles with multiple incumbents, several representative cases were requested. Job transitions might affect both the probability of the individual exiting the firm (a link between promotion and firm exits exists in the literature) and of being sampled in the case of continued employment (the likelihood of being sampled in the firm appears to rise at higher levels). For these reasons, sample attrition not due to firm non-participation is likely to be related to persistent individual factors that also affect promotion outcomes, making it endogenous. We therefore write the response probability (i.e. the probability that the worker is still present in the sample) as a function of the unobserved heterogeneity distribution and include the non-response probability in the individual's contribution to the likelihood when the firm is participating in the survey but not reporting on a particular executive.

We turn now to a formal description of the model. We first describe the promotion probabilities and then turn to attrition and unobserved heterogeneity. Finally, we write the likelihood function that is estimated.

\footnotetext{
${ }^{4}$ As already stated, movements of individuals across firms can not be identified. Therefore, we can not distinguish individual from firm persistent attributes. Without loss of generality, we refer to unobserved factors as individual specific.
} 


\subsection{Promotion Probability}

As already stated, the promotion indicator at year $t$ is defined as a job title change associated with a higher nominal pay grade midpoint between the year $t-1$ and year $t$.

The probability that individual $i$, belonging to firm $j$ is promoted at year $t$ is defined by the following equation:

$$
\begin{gathered}
\operatorname{Pr}\left(Y_{i j t}=1\right)=\Lambda\left(\beta_{r} \text { rmidage }_{i j t-1}+\beta_{q} L_{q i t-1}+\beta_{P O} P O_{i j t-1}+\beta_{F 1} F_{j t-1}\right. \\
\left.+\beta_{F 2}\left(F_{j t}-F_{j t-1}\right)+\beta_{U} U_{t-1}+\alpha_{i}\right)
\end{gathered}
$$

where:

- $\Lambda($.$) is the logistic cumulative distribution function.$

- rmidage $_{i j t-1}$ is the real pay grade midpoint divided by the executive's age. This variable measures the career advancement speed including the impact of recent in-sample promotions.

- $L_{q i t-1}$ is a set of binary variables indicating the reporting level of the executive in the firm. The value of the level, denoted $q$, is the number of reporting levels an executive is from the CEO position (level 1). Level 6 (or more) is the reference group and level 1 is not included because CEOs cannot be promoted internally.

- $P O_{i j t-1}$ measures the promotion opportunities in the firm. This variable is defined as the percentage of executives hired from outside the firm into positions above the given worker.

- $F_{j t}$ is a set of firm-specific variables. It includes profits, sales and total employment. The difference in these variables between periods $t-1$ and $t$ is also included.

- $U_{t-1}$ is the national unemployment rate. This variable allows general labor market conditions to be taken into account. It is possible that the state of the labor market or the state of business cycle will have an influence on turnover, hiring and promotions even after controlling for firm profits, sales and employment. 
- $\alpha_{i}$ is an individual specific term that represents individual unobserved heterogeneity. In order to resolve the initial condition problem, we specify its distribution conditional on the initial level (Wooldridge, 2005). Therefore, this term is decomposed into the sum of a regression component and an orthogonal unobserved component. More precisely, it takes the following form:

$$
\alpha_{i}=\alpha_{X} X_{i 0}+\alpha_{r} \text { rmidage }_{i 0}+\alpha_{U} U_{i H}+\alpha_{F A} F A_{i 0}+\widetilde{\alpha}_{i}
$$

where:

- $X_{i 0}$ contains human capital variables (age, education and tenure) and an indicator for newcomer status in the firm. All of these variables are measured as of the individual's first observation in the sample, that is before the first observable promotion occurs.

- rmidage $_{i 0}$ is the real pay grade midpoint divided by the executive's age also measured as of the executive's first observation in the sample. It captures the executive's prior career speed of advancement as of the start date in the sample. Including it allows the effect of the prior speed of advancement to be isolated from the effect of in-sample promotions to determine if in-sample promotions have a casual effect on subsequent promotion or whether fast tracks result only due to the greater prior career speed of advancement. In-sample promotions were shown to lead to a greater likelihood of subsequent promotion in the raw data.

- $U_{i H}$ is the yearly national unemployment rate measured at the time the executive was hired by the firm. This variable captures a potential long-lasting effect of labor market conditions when the individual entered the firm.

- $F A_{i 0}$ is a set of binary variables indicating the functional area to which the executive belongs at the beginning of the sample period. Differences in promotability based on functional area have been found in the management literature.

- $\widetilde{\alpha}_{i}$ is the orthogonal unobserved component; its distribution is defined more precisely below. 


\subsection{Response Probability}

As noted previously, attrition for an executive is caused either by the firm not participating in the survey or by the firm participating but not reporting on the particular executive. In our framework, we consider attrition as endogenous only when it is due to the latter reason. Attrition due to firm non-participation in the survey is considered as exogenous and is not included in the contribution to the likelihood.

The response probability at each period is written as a function of individual characteristics (the same unobserved heterogeneity component as in the promotion probability) and the variation of the number of executives reported by the firm from the previous period. More precisely, the probability that worker $i$, belonging to firm $j$, is observed at year $t$ is determined by the following expression:

$$
\operatorname{Pr}\left(Z_{i j t}=1\right)=\Lambda\left(\delta_{n} \% \Delta n b o b s_{j t}+\gamma_{i}\right)
$$

where:

- $\% \Delta n b o b s_{j t}$ is the relative variation of the number of workers reported by firm $j$ between years $t-1$ and $t$.

- $\gamma_{i}$ is an individual specific term that represents individual unobserved heterogeneity. Its expression takes a form close to the one adopted for $\alpha_{i}$ :

$$
\gamma_{i}=\gamma_{X} X_{i 0}+\gamma_{r} \text { rmidage }_{i 0}+\gamma_{U} U_{i H}+\gamma_{F A} F A_{i 0}+\widetilde{\gamma}_{i}
$$

where $X_{i 0}$, rmidage $_{i 0}, U_{i H}$ and $F A_{i 0}$ are the same set of variables as defined before, and $\widetilde{\gamma}_{i}$ is the orthogonal unobserved component. $\widetilde{\gamma}_{i}$ shares the same distribution as $\widetilde{\alpha}_{i}$, which is defined below.

Selectivity caused by attrition is thus corrected by allowing the same unobserved individual specific factors to affect promotion and response probabilities. This essentially means that we allow for the possibility that firm reporting behavior may be partly determined by unobserved heterogeneity, but do not model non-response explained by individual mobility decisions that would themselves be caused by promotion expectation (or lack thereof). On the other hand, our model can still account for attrition processes driven by mobility decisions as long as those decisions are not caused by current 
promotion outcomes but only correlated with it through a common heterogeneity factor.

To be more precise, our model does not allow for a dependence of attrition incidence on promotion outcomes since the stochastic term of the attrition outcome equation is orthogonal to promotion outcome. Allowing for it would either require allowing current promotion outcomes to enter the attrition equation or to specify a more structural model. While the former would raise serious identification issues, the latter would entail modeling the search and mobility decisions of executives and would require estimation efforts that are beyond the scope of the paper.

\subsection{Unobserved Heterogeneity}

In order to minimize the impact of distributional assumptions needed to implement this model, we assume that $\widetilde{\alpha}_{i}$ and $\widetilde{\gamma}_{i}$ are characterized by an unknown cumulative distribution function, $H($.$) , that is approximated using a$ discrete distribution (Heckman and Singer, 1984). The probability associated with type $k$ is

$$
p_{k}=\operatorname{Pr}\left(\widetilde{\alpha}_{i}=\alpha_{k}, \widetilde{\gamma}_{i}=\gamma_{k}\right),
$$

where $k=1, \ldots, K$. The optimal number of types, $K$, is determined from the minimization of the Bayesian Information Criterion when the model is estimated with $K$ ranging between 2 and 6 . The type probability, $p_{k}$, is estimated using a logistic transform:

$$
p_{k}=\frac{\exp q_{k}}{\sum_{s=1}^{K} \exp q_{s}} \quad k=1, \ldots, K,
$$

where $q_{k}$ s are parameters to be estimated with the restriction that $q_{K}=0$.

\subsection{Likelihood Function}

For a given year, the individual's contribution to the likelihood is the product of the response probability and the promotion probability. When the worker leaves the sample, he contributes to the likelihood only if this non-reporting results from the firm's decision to not participate in the survey at all. Therefore, the likelihood for an individual $i$ of type $k$ who is observed during $s$ 
periods, $s=1, \ldots, 7$, takes the following form:

$$
\begin{aligned}
L_{i}^{s}(k)= & \prod_{t=1}^{s}\left[\operatorname{Pr}\left(Z_{i j t}(k)=1\right) \cdot\left(\operatorname{Pr}\left(Y_{i j t}(k)=1\right)\right)^{d_{i t}} \cdot\left(1-\operatorname{Pr}\left(Y_{i j t}(k)=1\right)\right)^{1-d_{i t}}\right] \\
& \cdot\left(1-\operatorname{Pr}\left(Z_{i j s+1}(k)=1\right)\right)^{\left(a_{t t}\right)} .
\end{aligned}
$$

When the individual is only observed at the initial period and thus has no promotion observation, $s=0$, the likelihood function appears as:

$$
L_{i}^{0}(k)=\left(1-\operatorname{Pr}\left(Z_{i j 1}(k)=1\right)\right)^{\left(a t t_{i}\right)}
$$

The variable $d_{i t}$ is an indicator taking the value 1 if the individual is observed at period $t$ and $a t t_{i}$ is the attrition indicator variable equal to 1 when the worker has no observation at period $t$ and the firm is participating in the survey. Therefore, the likelihood of an individual of type $k$ is the following:

$$
L_{i}(k)=\prod_{s=0}^{7}\left[\left(L_{i}^{s}(k)\right)^{e_{i s}}\right]
$$

where $e_{i s}$ is an indicator variable taking the value 1 if the individual $i$ is observed during $s$ periods.

As a consequence, the mixed likelihood, for an individual $i$, is simply:

$$
L_{i}=\sum_{k=1}^{K} p_{k} \cdot L_{i}(k) .
$$

The model is estimated by maximization of the sum of all individual (mixed) $\log$ likelihoods.

\section{Empirical Results: The Determinants of Promotion}

The first step of our analysis is devoted to the model specification in which we distinguish between the spurious and the causal fast-track effects. As explained earlier, the distribution of unobserved heterogeneity includes a variable $\left(\right.$ rmidage $\left._{0}\right)$ that measures individual earnings achievements per year (real pay grade midpoint divided by age) as recorded when the individual 
enters the sample. This variable therefore captures the spurious fast-track effect whereas the variable $\left(\right.$ rmidage $\left._{t}\right)$, which measures past advancement up to year $t$, captures the causal fast-track effect.

We estimated several different versions of the model. These included specifications that modeled attrition and those that ignored the potential endogeneity of non-response. We also estimated both a static version of the model (with no causal fast-track) and a dynamic version. All versions were estimated with the unobserved heterogeneity distribution ranging from two to six types.

For brevity, we focus our presentation on the model that includes two types, which is the optimal number of types according to the Bayesian Information Criterion (values are provided in Table 5). Because virtually all models that incorporate an explicit modeling of non-response indicate a nontrivial degree of correlation between the unobserved heterogeneity component affecting non-response and the heterogeneity affecting promotions, we also focus on the model in which non-response (sample attrition) is endogenous.

The results are reported in three tables. The parameter estimates as well as their associated marginal effects on promotion probability are in Table 6. In Table 7, we report a variance decomposition of the promotion probability that allows the explanatory power of sets of variables to be examined (unobserved heterogeneity, in-sample career advancement speed, functional area, individual characteristics, reporting level, firm characteristics and the unemployment rate). Finally, in Table 8, we report measures of the correlation between the unobserved heterogeneity components explaining promotion and response and the correlation between promotion probability and response at period four. This allows the link between promotability and remaining in the sample (response) to be examined.

We also estimated a model similar to the one presented above but interacting in-sample pay grade advancement with reporting level. This specification allows more flexibility in the way the past speed of promotions affects the promotion probability. Parameter estimates are presented in Table 9 and the marginal effects of the past speed of promotions, specific to each reporting level in the firm, are reported in Table 10. 


\subsection{Investigating the Importance of Structural Fast- Tracks versus Unobserved Heterogeneity}

The first striking result is the coexistence of the very weak negative effect of the in-sample career advancement speed on subsequent promotion (the structural fast-track) with the strong positive effect of the initially observed career advancement speed in the initial condition equation on subsequent promotion (the spurious fast-track). The parameter estimate for the structural fast-track, -0.0763, implies that, after conditioning on unobserved heterogeneity, there is small negative effect on the promotion probability of -0.0029 for each 1,000 dollar gain in the pay grade midpoint per year. ${ }^{5}$ However, the lifetime yearly gain in the pay grade midpoint measured at the start of the sample is the main component of the unobserved heterogeneity equation, with a parameter estimate of 0.5014 , and a marginal effect that is more than six times greater. An increase in the average initial pay grade midpoint per year of $\$ 1,000$ increases the promotion probability by 0.0190 . In-sample promotions were associated with a substantial increase in the likelihood of subsequent promotion in the raw data. However, after conditioning on unobserved individual heterogeneity, there is no evidence that in-sample pay grade advancement increases subsequent promotion probabilities. This suggests that promotions, defined as a job change accompanied by an increase in the pay grade midpoint, in themselves do not have an inherent causal benefit on subsequent promotions, at least for relatively senior executives. It is possible that early career promotions could yet have a signaling aspect that would provide a benefit in subsequent promotions.

Interestingly, when we introduce an interaction term between in-sample pay grade advancement and the reporting level in the model, we find that in-sample advancement's marginal effect is positive at the lowest level of the hierarchy (level 6), not significant at intermediate levels (levels 3 to 5) and negative at the highest level (level 2). Indeed, results reported in Table 10 show that an increase in the average pay grade midpoint per year of $\$ 1,000$ increases the promotion probability by 0.0198 at the lowest level and decreases the promotion probability by 0.0098 at the highest level. The results for level 6 hint that an aspect of promotion signaling may exist at lower levels with younger workers. Overall, the results here strongly suggest that the

\footnotetext{
${ }^{5}$ In comparison, Belzil and Bognanno 2010 reported a negative causal fast track effect for the majority of the population with an almost negligible magnitude.
} 
source of widely noted executive fast tracks is unobserved individual factors, such as worker ability.

The standard human capital variables, such as age, education, and tenure, have a very limited impact on promotion. Education and firm tenure have a weak positive influence on promotion probabilities. Age and newcomer status have a weak negative effect. The marginal effects of age, newcomer status, education and tenure are $-0.0013,-0.0068,0.0014$ and 0.0002 respectively. ${ }^{6}$ The parameter estimates on the levels in the firm indicate that promotion probabilities diminish at the more senior levels. The positive influence of education on promotion after conditioning on unobserved individual heterogeneity is interesting in light of Devaro and Waldman's (2012) signaling model of promotion that produces the result that the performance level required for promotion is lower for more educated workers. We find support for their model's implication that, after controlling for worker preformance, higher levels of education should still be beneficial to promotion.

\subsection{Labor Market Conditions and Functional Area}

Our model takes into account the effect on promotion of both current labor market conditions and labor market conditions at the time the executive was hired. However, we find these measures have a minimal effect in estimations with measures of firm health included. The current rate of unemployment has a very slight dampening effect on promotion after accounting for firm profit, sales and employment. The marginal effect is -0.0016 . The unemployment rate measured when the executive was hired has no significant effect.

It is particularly interesting to note the degree of asymmetry in the effect and the level of significance of functional area indicators. The estimates indicate that those who work in marketing services, management areas and manufacturing seem to have a clear advantage in terms of future promotions. In terms of marginal effects, these estimates imply a higher annual promotion probability of 0.0177 for management, 0.016 for marketing and 0.0124 for manufacturing, relative to a material position (the reference functional area). The three weakest functional areas for promotion were employee relations, legal and management information systems. That differences in promotion

\footnotetext{
${ }^{6}$ Howard and Bray (1988) found a college degree to be the best predictor of promotion. Forbes and Piercy (1991, p. 165) find that the time to the CEO position is reduced through higher levels of education. Useem and Karabel (1986) show the importance of earning a degree from an elite institution when the executive is not from elite social origins.
} 
probabilities by functional area exist came to light in the management literature and are confirmed here.

\subsection{Decomposing Promotion Probabilities}

In order to assess the relative importance of each group of explanatory factors, we decompose the index function of the promotion probability. The explanatory power of each group of variables is measured by the $R^{2}$ of the regression of the promotion index function on the given group of variables. Results reported in Table 7 show that $70.6 \%$ of the total variation in promotion probabilities is explained by persistent unobserved heterogeneity. The next most important set of variable, age, education, tenure, newcomer status in the firm and unemployment upon hire, accounts for $8.3 \%$. The functional areas account for $5.4 \%$. Firm variables (sales, profits and employment measured in levels and changes) and the indicator of promotion opportunities seem to have only a minimal explanatory power, as they explain only $3.3 \%$ of the variation. Initially observed career advancement speed accounts for 2.0\%. Career advancement speed updated each sample year accounts for 1.6\%. Reporting level and the in-sample unemployment rate each account for $0.5 \%$. So, clearly, unobservable factors are much more influential than the factors that we are able to observe.

\subsection{Correlation between Promotion and Response Prob- abilities}

We now examine the correlation between the unobserved heterogeneity components of promotion outcomes and response. To interpret it, one should recall that our model assumes implicitly that the response probability is exogenous from the perspective of the executive but that the decision of the firm to report or not a particular individual may depend on the executive's heterogeneity. The estimate, found in Table 8, is positive and equal to 0.467. It is sizable and it generally indicates that those who are more likely to be promoted are also more likely to remain in the sample.

As mentioned earlier, both individual mobility decisions and firm reporting behavior act as simultaneous mechanisms. Regarding mobility, Baker, Gibbs and Holmstrom (1994a) and Treble, van Gameren, Bridges and Barmby (2001) have documented fast-track exit effects (those promoted more quickly 
having a higher exit rate from the firm). However, despite the positive correlation between mobility and promotability reported in the literature, economic theory has nothing to say about firm reporting decisions. Because the data do not allow us to separate them, it is not possible to give a definite explanation for this positive correlation. We would simply highlight the possibility that the positive correlation that we find is not incompatible with the existence of a negative correlation between unobserved heterogeneity affecting promotions and true mobility decisions.

To summarize, the empirical evidence displayed in Tables 6, 7 and 8, as well as results obtained from specifications that are not reported, suggest that the promotion process may be summarized by a static discrete outcome model, where all serial correlation is accounted for by persistent individual unobserved factors.

\section{Conclusion}

In this paper, we estimate a dynamic reduced-form model of promotions on a panel of high-level executives employed in over 300 U.S.corporations. Promotion is defined as a change in job title resulting in a higher pay grade midpoint. The promotion probability is written as a function of variables taken at their value when the individual is first observed in the sample, including observed individual characteristics (age, education, tenure, and newcomer status in the firm), the initially observed career advancement speed in pay grade, the unemployment rate and functional area, and variables that are updated each sample year, including career advancement speed, reporting level, firm characteristics and labor market conditions. The specification controls for unobserved individual heterogeneity and allows an endogenous initial condition and endogenous sample attrition.

Many studies in the personnel economics literature have found evidence of fast tracks but did not determine their source. This is a principle contribution of this paper. Executives observed to be promoted quickly appeared to have more rapid subsequent promotions. Evidence consistent with this notion was found here in a simple examination of the raw data in that executives with an in-sample promotion were more likely to receive a subsequent promotion. The cause of this phenomena has been hypothesized to result from the potential signaling effect of promotion but also simply from the persistent benefit of a promoted executive being of higher ability. No evidence is found that an 
executive's speed of advancement in pay grade updated each sample year has a positive causal impact on promotions after conditioning on the executive's past career speed of advancement in estimations that force the effect of the executive's speed of advancement on promotion to be the same across reporting levels. In these estimations, the in-sample career advancement speed has a weakly negative marginal effect on promotion. For the high-level executives in these data overall, fast tracks appear to result from heterogeneity in persistent individual characteristics, not from an inherent benefit in the recent advancement itself. Thus, the notion of fast tracks resulting from the persistent benefit of being of high ability is supported over the notion that fast tracks result from the signaling effect of promotions.

However, in an estimation that allows the effect of the executive's speed of advancement on promotion to vary by reporting level, the results are more nuanced. In-sample promotions do have a positive effect on the promotion probability of executives at least five reporting levels beneath the CEO. This finding suggests that promotion signaling may contribute to fast tracks for lower level executives. The same specification was not estimated in our prior paper though that paper did find fast tracks for a minority of executives, those at lower levels with less education and tenure. The finding that promotion signaling may contribute to fast tracks for lower level employees is interesting because promotion signals would intuitively be expected to be the strongest for this group. DeVaro and Waldman (2012) derive the theoretical implication that, for less educated workers, both the performance level required for promotion and the wage change upon promotion are higher and state that these implications hold more strongly for initial promotions than for subsequent promotions. This suggests that the strongest signals to the outside labor market should come from the promotion of less educated, lower level executives with a shorter history of prior promotions. The support found for promotion signaling(at least at low levels) aligns with other papers finding empirical support for the notion of promotion signaling in tests unrelated to fast tracks (such as Bognanno and Melero 2016, Cassidy, H., J. DeVaro, and A. Kauhanen 2014, DeVaro and Waldman 2012 and Okamura 2012).

The large majority of the variation in promotion probabilities is explained by persistent unobserved individual heterogeneity, about $71 \%$. All observable variables combined, including age, education, tenure, functional area, reporting level, the unemployment rate and firm profits, sales and employment, account for just over $20 \%$ of the variation in promotion probabilities. 
This would make predicting promotion purely on the basis of observable characteristics for senior executives difficult. It is impossible to know the extent to which richer information is known within the firm that would make promotion predictions easier to make. Uncertainty in regards to promotion may serve the firm's interests if promotion tournament incentives are beneficial.

The management literature noted long ago that differences in promotion existed across functional areas. Our results support this finding. Promotion probabilities differ by functional area for executives at the same reporting level and firm. Executives initially observed in marketing, management and manufacturing had higher annual promotion probabilities. Those in employee relations, legal and management information systems had lesser annual promotion probabilities. The differences in promotion probabilities by functional area were evident even after controlling for observable individual characteristics. The different functional areas as a group account for about $5 \%$ of the variation in promotion probabilities.

In terms of future research, along the lines of the work of DeVaro and Waldman (2012), it would be interesting to see if the wage change upon promotion is the largest for those workers who appear ex ante to be the least likely to be promoted. Theoretically, a promotion in these cases should send the strongest signal to the outside labor market and force the largest wage increase from the current firm. 


\section{References}

Abowd, J.M. 1990. "Does Performance-Based Managerial Compensation Affect Corporate Performance?" Industrial and Labor Relations Review 43:52S-73S, Special Issue: Do Compensation Policies Matter?

Ariga, K., Y. Ohkusa, and G. Brunello. 1999. "Fast Track: is it in the Genes? The Promotion Policy of a Large Japanese Firm." Journal of Economic Behavior \& Organization 38:385-402.

Baker, G., M. Gibbs, and B. Holmstrom. 1994a. "The Internal Economics of the Firm: Evidence from Personnel Data." The Quarterly Journal of Economics 109:881-919.

—. 1994b. "The Wage Policy of a Firm." The Quarterly Journal of Economics 109:921-955.

Beaudry, P., and J. DiNardo. 1991. "The Effect of Implicit Contracts on the Movement of Wages Over the Business Cycle: Evidence from Micro Data." Journal of Political Economy 99:665-688.

Belzil, C., and M.L. Bognanno. 2010. "The Promotion Dynamics of American Executives." Research in Labor Economics 30:189-231.

-. 2008. "Promotions, Demotions, Halo Effects, and the Earnings Dynamics of American Executives." Journal of Labor Economics 26:287-310.

Bernhardt, D. 1995. "Strategic Promotion and Compensation." The Review of Economic Studies 62:315-339.

Bognanno, M.L. 2001. "Corporate Tournaments." Journal of Labor Economics 19:290-315.

Bognanno, M.L., and E. Melero. 2012. "Promotion Signals, Age and Education." IZA Discussion Paper No. 6431, March.

Cassidy, H., J. DeVaro, and A. Kauhanen. 2012. "The Signaling Role of Promotions: New Evidence from European Firms." Mimeo, Department of Economics, California State University, East Bay, December.

Chiappori, P.A., B. Salanié, and J. Valentin. 1999. "Early Starters versus Late Beginners." Journal of Political Economy 107:731-760. 
Clemens, A. 2012. "Position-Specific Promotion Rates and the "Fast Track" Effect." Research in Labor Economics 36:77-107.

DeVaro, J., and M. Waldman. 2012. "The Signaling Role of Promotions: Further Theory and Empirical Evidence." Journal of Labor Economics 30:91-147.

Dohmen, T.J., B. Kriechel, and G.A. Pfann. 2004. "Monkey Bars and Ladders: The Importance of Lateral and Vertical Job Mobility in Internal Labor Market Careers." Journal of Population Economics 17:193-228.

Forbes, J.B., and J.E. Piercy. 1991. Corporate Mobility and Paths to the Top: Studies for Human Resource and Management Development Specialists, G. Press, ed. New York: Quorum Books.

Gibbons, R., and M. Waldman. 1999. "A Theory of Wage and Promotion Dynamics Inside Firms." Quarterly Journal of Economics 114:1321-1358.

Gibbs, M., and W. Hendricks. 2004. "Do Formal Salary Systems Really Matter?" Industrial and Labor Relations Review 58:71-93.

Heckman, J.J., and B. Singer. 1984. "A Method for Minimizing the Impact of Distributional Assumptions in Econometric Models for Duration Data." Econometrica 52:271-320.

Howard, A., and D.W. Bray. 1988. Managerial Lives in Transition: Advancing Age and Changing Times. New York: The Guilford Press.

Kauhanen, A., and S. Napari. 2012. "Career and Wage Dynamics: Evidence from Linked Employer-Employee Data." Research in Labor Economics 36:35-76.

Kwon, I., E. Meyersson Milgrom, and S. Hwang. 2010. "Cohort Effects in Promotions and Wages." The Journal of Human Resources 45:772-808.

Lazear, E.P. 1992. "The Job as a Concept." In W. J. J. Bruns, ed. Performance Measurement, Evaluation, and Incentives. Boston: Harvard Business School Press, pp. 183-216.

Okamura, K. 2011. "The Signalling Role of Promotions in Japan." Discussion Paper No. 1112, Graduate School of Economics, Kobe University. 
Pergamit, M.R., and J.R. Veum. 1999. "What is a Promotion?" Industrial and Labor Relations Review 52:581-601.

Rosenbaum, J.E. 1979. "Tournament Mobility: Career Patterns in a Corporation." Administrative Science Quarterly 24:220-241.

Seltzer, A., and D. Merrett. 2000. "Personnel Policies at the Union Bank of Australia: Evidence from the 1888-1900 Entry Cohorts." Journal of Labor Economics 18:573-613.

Treble, J., E. van Gameren, S. Bridges, and T. Barmby. 2001. "The Internal Economics of the Firm: Further Evidence from Personnel Data." Labour Economics 8:531-552.

Useem, M., and J. Karabel. 1986. "Pathways to Top Corporate Management." American Sociological Review 51:184-200.

Vroom, V.H., and K.R. MacCrimmon. 1968. "Toward a Stochastic Model of Managerial Careers." Administrative Science Quarterly 13:26-46.

Waldman, M. 1984. "Job Assignments, Signalling, and Efficiency." The RAND Journal of Economics 15:255-267.

Wooldridge, J.M. 2005. "Simple Solutions to the Initial Conditions Problem in Dynamic, Nonlinear Panel Data Models with Unobserved Heterogeneity." Journal of Applied Econometrics 20:39-54. 


\section{Tables}

Table 1: Summary Statistics of the Sample Used in the Estimations

\begin{tabular}{|c|c|c|c|c|c|c|c|c|}
\hline Year & 1981 & 1982 & 1983 & 1984 & 1985 & 1986 & 1987 & 1988 \\
\hline Individuals & 13,113 & 13,113 & 8,728 & 6,280 & 4,400 & 2,864 & 2,053 & 1,435 \\
\hline \multicolumn{9}{|l|}{ Compensation Variables } \\
\hline $\begin{array}{l}\text { Total Compensation } \\
\text { (units of } 10,000 \text { 1980USD) }\end{array}$ & $\begin{array}{c}7.8 \\
(6.9)\end{array}$ & $\begin{array}{c}8.1 \\
(7.2)\end{array}$ & $\begin{array}{c}8.5 \\
(7.3)\end{array}$ & $\begin{array}{c}9.4 \\
(8.2)\end{array}$ & $\begin{array}{l}10.2 \\
(9.3)\end{array}$ & $\begin{array}{l}10.6 \\
(9.8)\end{array}$ & $\begin{array}{c}11.7 \\
(11.3)\end{array}$ & $\begin{array}{c}12.9 \\
(12.5)\end{array}$ \\
\hline $\begin{array}{l}\text { Mean Base Pay } \\
\text { (units of } 10,000 \text { 1980USD) }\end{array}$ & $\begin{array}{c}6.2 \\
(4.3)\end{array}$ & $\begin{array}{c}6.4 \\
(4.5)\end{array}$ & $\begin{array}{c}6.9 \\
(4.9)\end{array}$ & $\begin{array}{l}7.4 \\
(5.3)\end{array}$ & $\begin{array}{l}7.8 \\
(5.8)\end{array}$ & $\begin{array}{c}8.1 \\
(6.1)\end{array}$ & $\begin{array}{l}8.6 \\
(6.3)\end{array}$ & $\begin{array}{c}9.3 \\
(7.0)\end{array}$ \\
\hline $\begin{array}{l}\text { Mean Bonus } \\
\text { (units of } 10,000 \text { 1980USD) }\end{array}$ & $\begin{array}{c}1.6 \\
(3.0) \\
\end{array}$ & $\begin{array}{c}1.7 \\
(3.1)\end{array}$ & $\begin{array}{c}1.6 \\
(2.8) \\
\end{array}$ & $\begin{array}{c}2.0 \\
(3.4)\end{array}$ & $\begin{array}{c}2.4 \\
(4.1)\end{array}$ & $\begin{array}{c}2.5 \\
(4.2)\end{array}$ & $\begin{array}{c}3.2 \\
(5.8) \\
\end{array}$ & $\begin{array}{c}3.6 \\
(6.0) \\
\end{array}$ \\
\hline \multicolumn{9}{|c|}{ Changes in Firm Variables and Promotion Rates } \\
\hline$\% \Delta$ sales & & $\begin{array}{l}2.9 \% \\
(22 \%)\end{array}$ & $\begin{array}{l}2.1 \% \\
(44 \%)\end{array}$ & $\begin{array}{c}0.1 \% \\
(15 \%)\end{array}$ & $\begin{array}{c}7.3 \% \\
(13 \%)\end{array}$ & $\begin{array}{l}-0.5 \% \\
(26 \%)\end{array}$ & $\begin{array}{c}10.2 \% \\
(101 \%)\end{array}$ & $\begin{array}{c}5.3 \% \\
(11 \%)\end{array}$ \\
\hline$\% \Delta$ profits & & $\begin{array}{l}11 \% \\
(88 \%)\end{array}$ & $\begin{array}{c}28 \% \\
(610 \%)\end{array}$ & $\begin{array}{c}46 \% \\
(291 \%)\end{array}$ & $\begin{array}{c}84 \% \\
(422 \%)\end{array}$ & $\begin{array}{c}60 \% \\
(915 \%)\end{array}$ & $\begin{array}{c}-3 \% \\
(252 \%)\end{array}$ & $\begin{array}{l}143 \% \\
(812 \%)\end{array}$ \\
\hline$\% \Delta$ employment & & $\begin{array}{c}2.1 \% \\
(19 \%)\end{array}$ & $\begin{array}{l}1.5 \% \\
(36 \%)\end{array}$ & $\begin{array}{c}0.1 \% \\
(13 \%)\end{array}$ & $\begin{array}{l}4.4 \% \\
(19 \%)\end{array}$ & $\begin{array}{l}1.2 \% \\
(19 \%)\end{array}$ & $\begin{array}{c}5.7 \% \\
(79 \%)\end{array}$ & $\begin{array}{l}1.8 \% \\
(14 \%)\end{array}$ \\
\hline Annual Mean Promotion* & & $\begin{array}{c}0.09 \\
(0.28) \\
\end{array}$ & $\begin{array}{c}0.08 \\
(0.27) \\
\end{array}$ & $\begin{array}{c}0.09 \\
(0.28) \\
\end{array}$ & $\begin{array}{c}0.10 \\
(0.30) \\
\end{array}$ & $\begin{array}{c}0.10 \\
(0.30) \\
\end{array}$ & $\begin{array}{c}0.08 \\
(0.27) \\
\end{array}$ & $\begin{array}{c}0.07 \\
(0.26) \\
\end{array}$ \\
\hline \multicolumn{9}{|c|}{ Executive Characteristics in 1981} \\
\hline Firm Tenure & 15.1 & $(10.5)$ & & & & & & \\
\hline Reporting Level & 4.3 & (1.4) & & & & & & \\
\hline Years in Position & 4.0 & $(3.9)$ & & & & & & \\
\hline Age & 47.4 & $(8.7)$ & & & & & & \\
\hline Education & 16.2 & $(1.9)$ & & & & & & \\
\hline
\end{tabular}

* The promotion indicator takes the value 1 if the executive experiences a change in job title associated with a higher pay grade midpoint, 0 if not.

Note: Standard deviations under parenthesis. 
Table 2: Level versus Job Title in Pay Determination

\begin{tabular}{|c|c|c|c|c|}
\hline \multicolumn{5}{|c|}{ OLS } \\
\hline Dependent & $\ln ($ & & \multirow{2}{*}{\multicolumn{2}{|c|}{ ln (Base Pay) }} \\
\hline Variable & Compe & ation) & & \\
\hline Intercept & $12.08^{* * *}$ & $(0.005)$ & $11.78^{* * *}$ & $(0.004)$ \\
\hline Job Title Promotion Index & $0.13^{* * *}$ & $(0.004)$ & $0.10^{* * *}$ & $(0.003)$ \\
\hline Reporting Level & $-0.23^{* * *}$ & $(0.001)$ & $-0.20^{* * *}$ & $(0.001)$ \\
\hline $\mathrm{N}$ & \multicolumn{2}{|c|}{107,359} & \multicolumn{2}{|c|}{107,359} \\
\hline$R^{2}$ & \multicolumn{2}{|c|}{0.30} & \multicolumn{2}{|c|}{0.31} \\
\hline \multicolumn{5}{|c|}{ Individual Fixed Effects } \\
\hline Dependent & \multirow{2}{*}{\multicolumn{2}{|c|}{$\begin{array}{c}\ln (\text { Total } \\
\text { Compensation) }\end{array}$}} & \multirow{2}{*}{\multicolumn{2}{|c|}{ ln (Base Pay) }} \\
\hline Variable & & & & \\
\hline Job Title Promotion Index & $0.15^{* * *}$ & $(0.001)$ & $0.13^{* * *}$ & $(0.001)$ \\
\hline Reporting Level & $-0.02^{* * *}$ & $(0.001)$ & $-0.02^{* * *}$ & $(0.001)$ \\
\hline $\mathrm{N}$ & \multicolumn{2}{|c|}{107,359} & \multicolumn{2}{|c|}{107,359} \\
\hline$R^{2}$ & \multicolumn{2}{|c|}{0.97} & \multicolumn{2}{|c|}{0.98} \\
\hline
\end{tabular}

Note 1: The job title promotion index is set to 0 in the first year an executive appears in the data and is updated by +1 for subsequent promotions and -1 for demotions.

Note 2: Standard errors under parenthesis. Significance levels: $* * * 1 \% ; * * 5 \% ; * 10 \%$. 
Table 3: Pay and Transition Outcomes Subsequent to Initial Transition

\begin{tabular}{|c|c|c|c|c|}
\hline $\begin{array}{l}\text { Transition between } \\
\text { years } 1 \text { and } 2\end{array}$ & Non-Mover & Promoted & Lateral Mover & Demoted \\
\hline \multirow{4}{*}{$\begin{array}{l}\text { Transition } \\
\text { Definition }\end{array}$} & \multirow{4}{*}{$\begin{array}{l}\text { Same job } \\
\text { title }\end{array}$} & New job title & New job title & New job title \\
\hline & & \& higher & \& same & \& lower \\
\hline & & nominal & nominal & nominal \\
\hline & & pay grade & pay grade & pay grade \\
\hline$\%$ of sample & $90.1 \%$ & $8.0 \%$ & $1.2 \%$ & $0.7 \%$ \\
\hline \multicolumn{5}{|c|}{$\Delta$ Years 1 and 2: Initial Pay Changes and Transitions } \\
\hline$\% \Delta$ Total Compensation & $5.4 \%$ & $11.4 \%$ & $7.0 \%$ & $2.9 \%$ \\
\hline$\% \Delta$ Base Pay & $3.2 \%$ & $9.2 \%$ & $5.2 \%$ & $1.6 \%$ \\
\hline$\% \Delta$ Bonus & $23.7 \%$ & $28.1 \%$ & $14.3 \%$ & $3.1 \%$ \\
\hline$\% \Delta$ Pay Grade Midpoint & $8.1 \%$ & $19.2 \%$ & $0.0 \%$ & $-10.0 \%$ \\
\hline Non-Mover & $100.0 \%$ & & & \\
\hline Promoted & & $100.0 \%$ & & \\
\hline Lateral Mover & & & $100.0 \%$ & \\
\hline Demoted & & & & $100.0 \%$ \\
\hline $\mathrm{N}($ total $=28,162)$ & 25,380 & 2,247 & 348 & 187 \\
\hline \multicolumn{5}{|c|}{$\begin{array}{l}\Delta \text { Years } 2 \text { and 3: Subsequent Pay Changes and Transitions } \\
\text { by Initial Transition Outcome }\end{array}$} \\
\hline$\% \Delta$ Total Compensation & $3.8 \%$ & $6.7 \%$ & $7.0 \%$ & $3.3 \%$ \\
\hline$\% \Delta$ Base Pay & $4.4 \%$ & $5.4 \%$ & $5.9 \%$ & $4.0 \%$ \\
\hline$\% \Delta$ Bonus & $10.0 \%$ & $19.5 \%$ & $28.0 \%$ & $0.0 \%$ \\
\hline$\% \Delta$ Pay Grade Midpoint & $6.9 \%$ & $7.1 \%$ & $12.9 \%$ & $19.5 \%$ \\
\hline Non-Mover & $89.8 \%$ & $81.1 \%$ & $77.6 \%$ & $81.5 \%$ \\
\hline Promoted & $7.9 \%$ & $13.8 \%$ & $17.1 \%$ & $16.7 \%$ \\
\hline Lateral Mover & $1.6 \%$ & $3.5 \%$ & $3.3 \%$ & $0.0 \%$ \\
\hline Demoted & $0.8 \%$ & $1.7 \%$ & $1.9 \%$ & $13.5 \%$ \\
\hline $\mathrm{N}($ total $=17,954)$ & 16,126 & 1,510 & 210 & 108 \\
\hline \multicolumn{5}{|c|}{$\begin{array}{l}\Delta \text { Years } 3 \text { and 4: Subsequent Pay Changes and Transitions } \\
\text { by Initial Transition Outcome }\end{array}$} \\
\hline$\% \Delta$ Total Compensation & $6.8 \%$ & $8.3 \%$ & $9.2 \%$ & $5.3 \%$ \\
\hline$\% \Delta$ Base Pay & $4.4 \%$ & $5.7 \%$ & $5.5 \%$ & $3.0 \%$ \\
\hline$\% \Delta$ Bonus & $26.7 \%$ & $29.4 \%$ & $18.1 \%$ & $6.5 \%$ \\
\hline$\% \Delta$ Pay Grade Midpoint & $7.3 \%$ & $9.1 \%$ & $9.3 \%$ & $10.7 \%$ \\
\hline Non-Mover & $89.4 \%$ & $82.0 \%$ & $72.4 \%$ & $78.8 \%$ \\
\hline Promoted & $8.9 \%$ & $15.1 \%$ & $18.1 \%$ & $19.7 \%$ \\
\hline Lateral Mover & $0.9 \%$ & $1.6 \%$ & $5.2 \%$ & $1.5 \%$ \\
\hline Demoted & $0.7 \%$ & $1.3 \%$ & $4.3 \%$ & $0.0 \%$ \\
\hline $\mathrm{N}($ total $=12,164)$ & 10,942 & 1,040 & 116 & 66 \\
\hline
\end{tabular}


Table 4: Potential Leading Indicators of Promotion: Prior Pay, Human Capital and Transitions

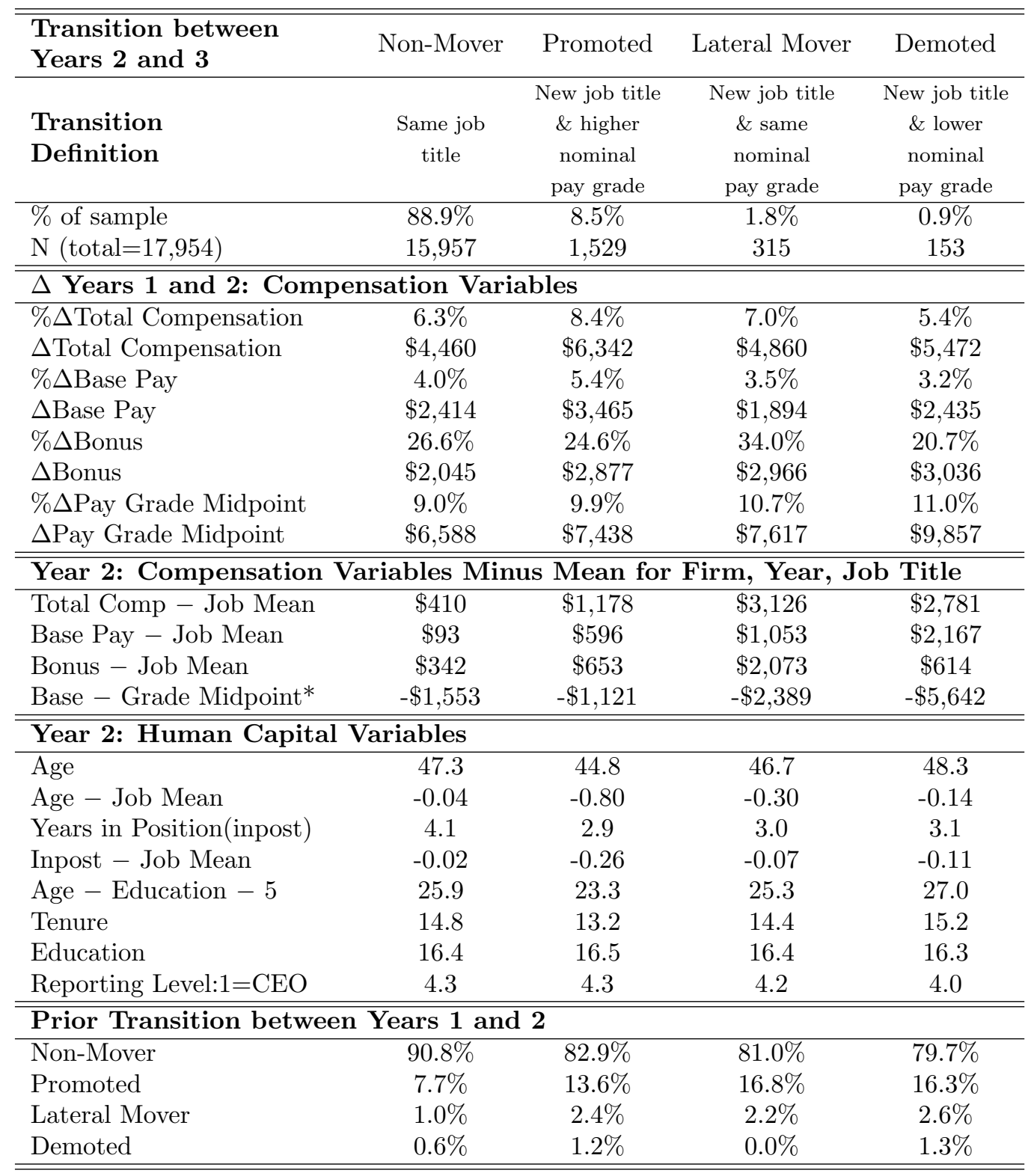

* Only $43 \%$ of executives receive base pay at or above their real pay grade midpoint. 
Table 5: Bayesian Information Criterion Values for Model Selection

\begin{tabular}{lcc}
\hline \hline & $\log (\mathrm{L})$ & $\mathrm{BIC}$ \\
\hline 1 type & $-58,411.93$ & $11,7299.92$ \\
2 types & $-58,324.39$ & $11,7155.89$ \\
3 types & $-58,315.47$ & $11,7169.09$ \\
4 types & $-58,315.01$ & $11,7199.21$ \\
5 types & $-58,314.67$ & $11,7229.59$ \\
6 types & $-58,314.15$ & $11,7259.59$ \\
\hline \hline
\end{tabular}




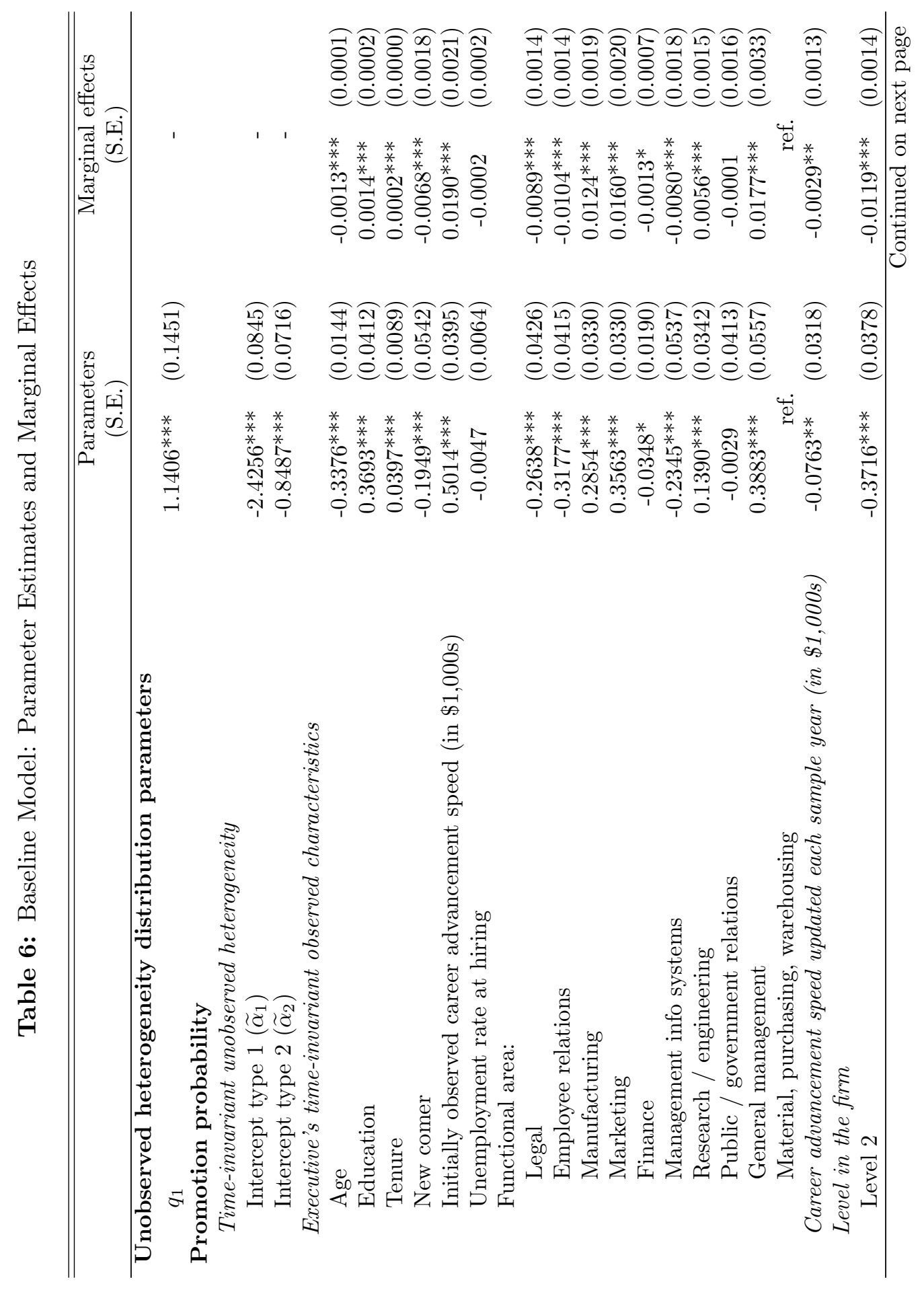




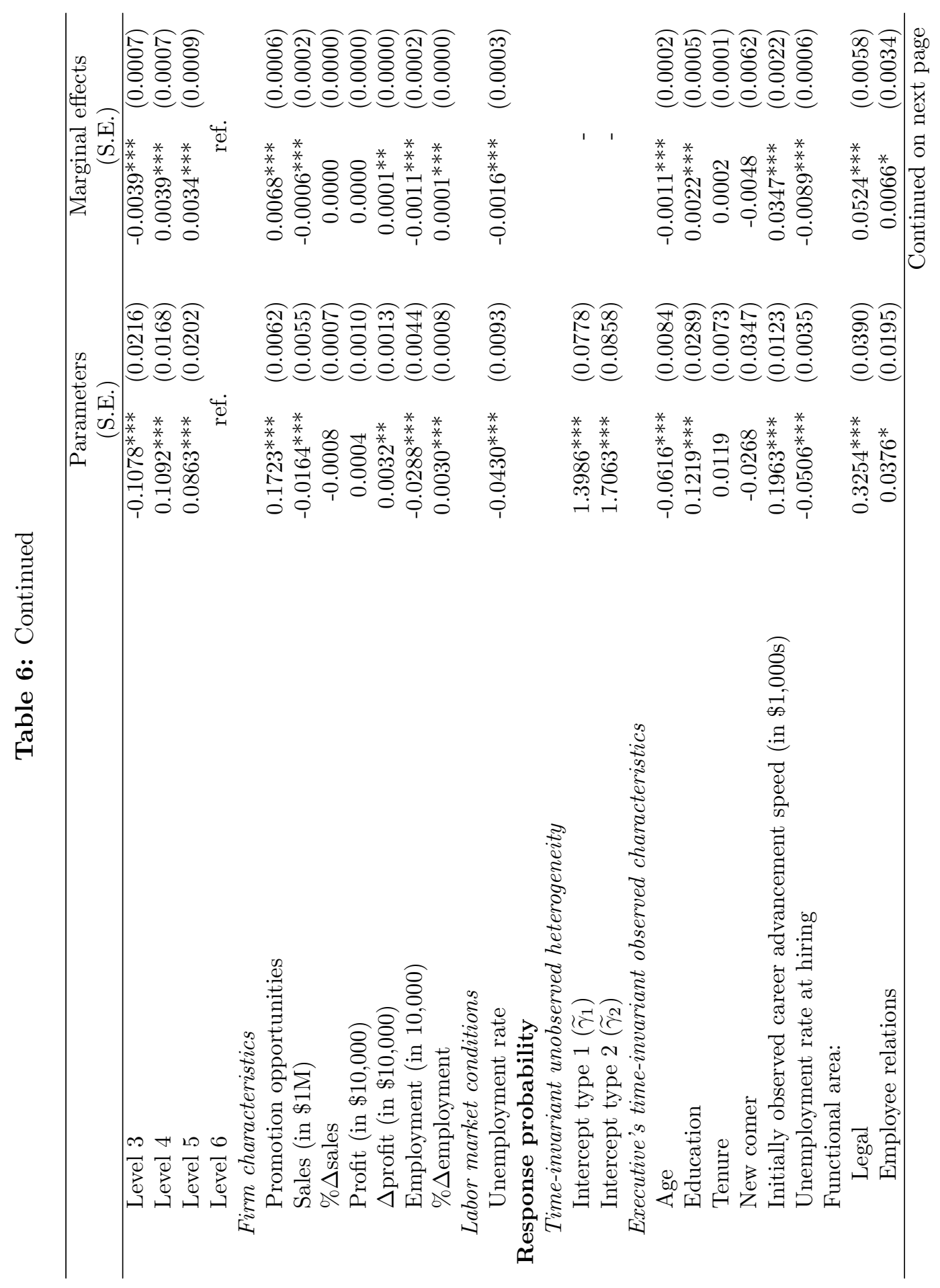




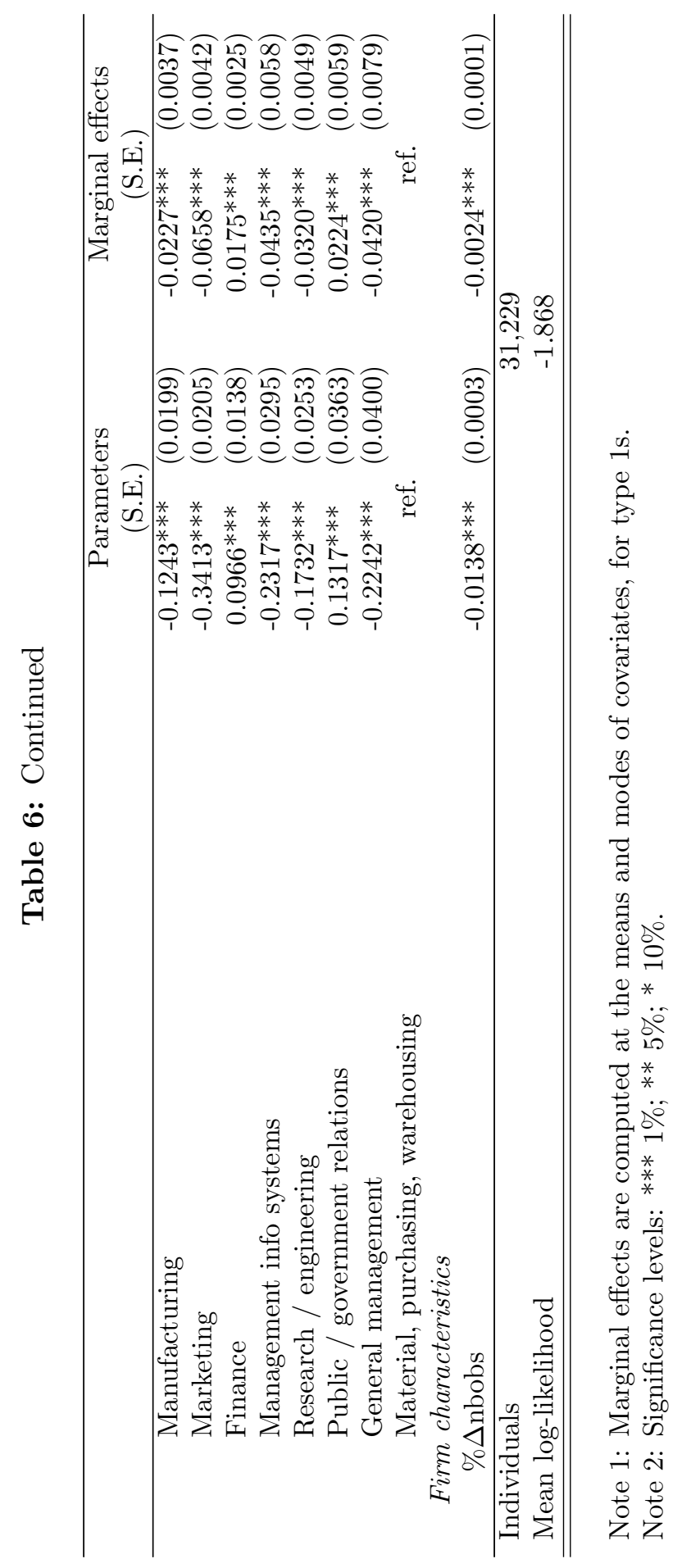


Table 7: Baseline Model: Variance Decomposition of the Promotion Probability

\begin{tabular}{lc}
\hline \hline Time-invariant unobserved heterogeneity & 0.706 \\
Initially observed career advancement speed (in $\$ 1,000 \mathrm{~s})$ & 0.020 \\
Functional area & 0.054 \\
Age, education, tenure, new comer status, unemployment at time of hire & 0.083 \\
Career advancement speed updated each sample year & 0.016 \\
Reporting level in the firm & 0.005 \\
Firm characteristics & 0.033 \\
Unemployment rate & 0.005 \\
All variables & $\mathbf{0 . 9 0 7}$ \\
\hline \hline
\end{tabular}

Note 1: The variance decomposition is performed on all individuals observed at period 4

Note 2: The share of the variance explained by each factor is measured by the $R^{2}$ of the predicted promotion probability regressed on the variables associated to the factor.

Table 8: Baseline Model: Correlation Between Promotability and Response

\begin{tabular}{lc}
\hline \hline $\operatorname{corr}\left(\alpha_{i}, \gamma_{i}\right)$ & 0.467 \\
$\operatorname{corr}\left(\operatorname{Pr}\left(Y_{i j 4}=1\right), \operatorname{Pr}\left(Z_{i j 4}=1\right)\right)$ & 0.268 \\
\hline \hline
\end{tabular}

Note: The first line corresponds to the coefficient of correlation between the executive's time-invariant specific (unobserved and observed) components of promotion and response probabilities. The second line corresponds to the coefficient of correlation between the probabilities of promotion and response at period 4 . 


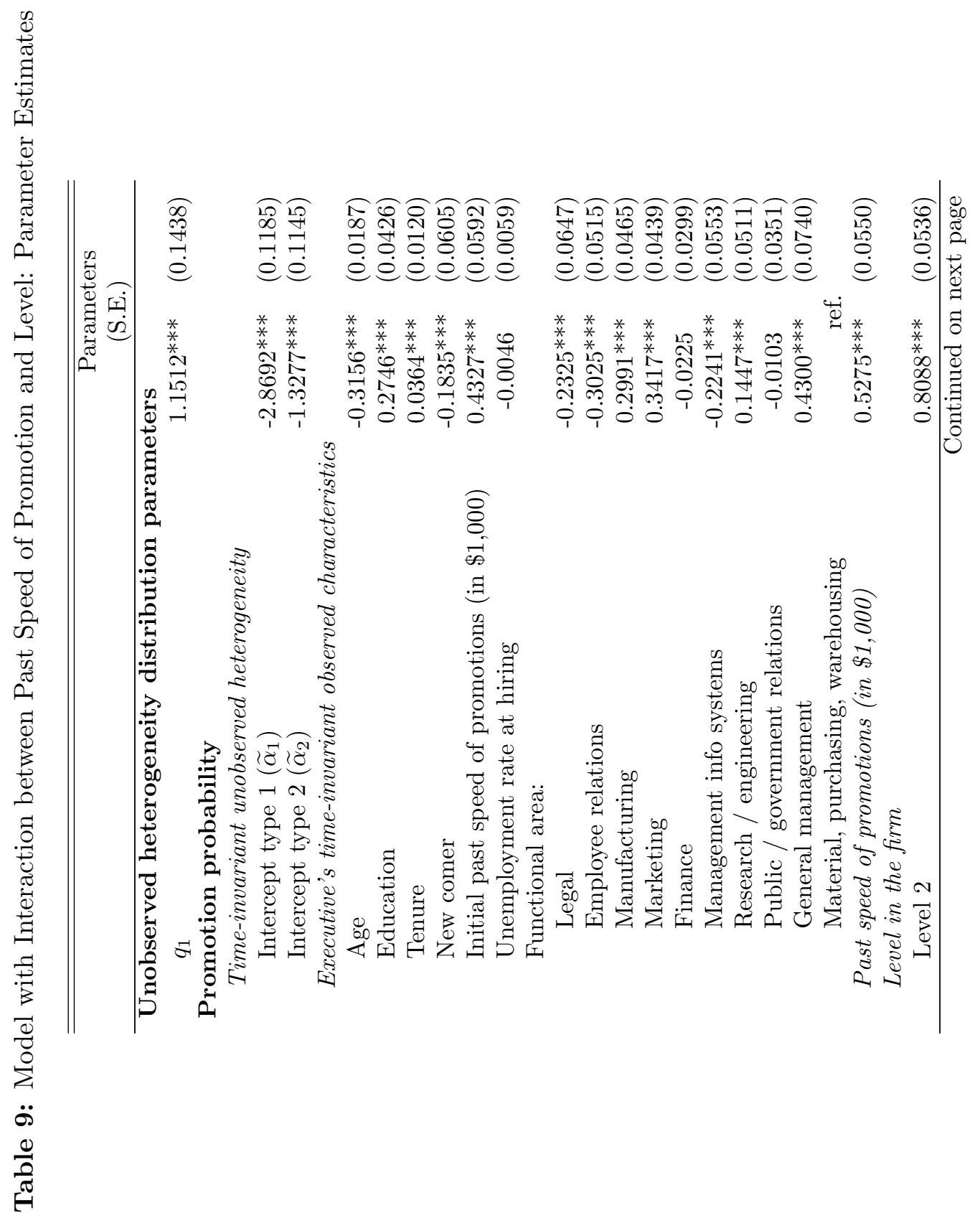




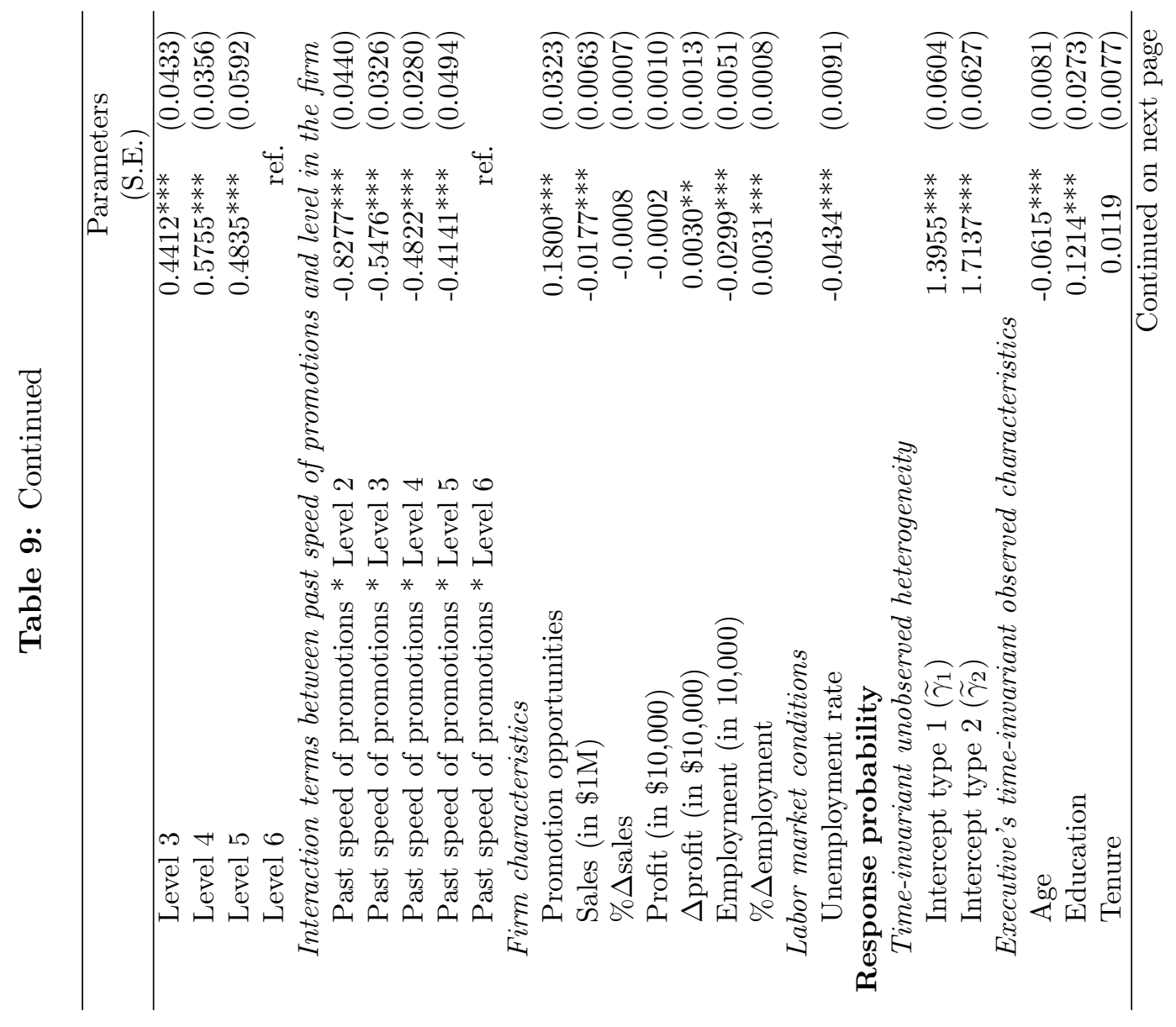




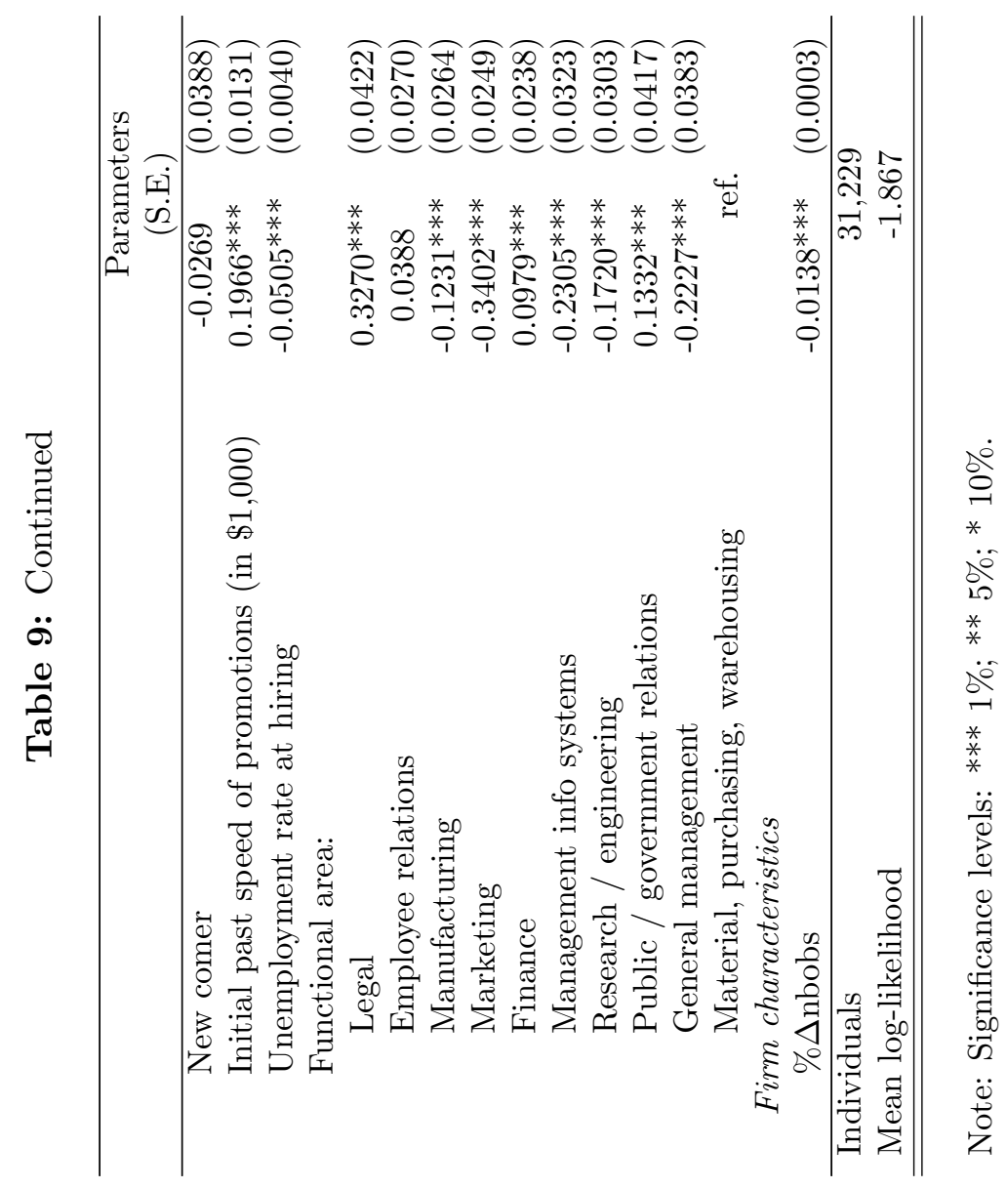


Table 10: Model with Interaction between Past Speed of Promotion and Level in the Firm: Marginal Effect of the Past Speed of Promotions at the Different Levels in the Firm

\begin{tabular}{lcc}
\hline \hline & \multicolumn{2}{c}{$\begin{array}{c}\text { Marginal effect } \\
\text { (S.E.) }\end{array}$} \\
\hline Marginal effect of the past speed of promotions at level 2 & $-0.0098^{* * *}(0.0015)$ \\
Marginal effect of the past speed of promotions at level 3 & -0.0006 & $(0.0017)$ \\
Marginal effect of the past speed of promotions at level 4 & 0.0017 & $(0.0024)$ \\
Marginal effect of the past speed of promotions at level 5 & 0.0043 & $(0.0030)$ \\
Marginal effect of the past speed of promotions at level 6 & $0.0198^{* * *}$ & $(0.0030)$ \\
\hline \hline
\end{tabular}

Note: The marginal effects reported in this table have been computed from parameter estimates presented in Table 9. 